\title{
Hyperresponsiveness of Cardiac Muscles to Histamine in Reserpine-Treated Guinea Pigs
}

\author{
Nobuyuki Okazaki, M.Sc., Kouichi Tanonaka, Ph.D., \\ Yoshihisa Nasa, Ph.D., Norio TaKagi, M.Sc., \\ Takashi Yamasaki, M.Sc., Shoji Yoshida, B.Sc., \\ and Satoshi TAKEO, Ph.D.
}

\begin{abstract}
SUMMARY
The hyperresponsiveness of cardiac tissue to histamine following treatment with reserpine was pharmacologically characterized. Guinca pig hearts were isolated 24 hours after intraperitoneal administration of $5 \mathrm{mg} / \mathrm{kg}$ reserpine. This treatment resulted in a complete depletion of tissue norepinephrine. Reserpine treatment potentiated the positive inotropic response of isolated perfused hearts to histamine at doses ranging from 0.3 to $3 \mu \mathrm{g}$ (23 to $57 \%$ increase for reserpine-treated animals vs. 14 to $32 \%$ increase for control animals). Isolated left ventricular papillary muscle of reserpine-treated guinea pig hearts also showed hyperresponsiveness to histamine at concentrations of 0.1 $\mu \mathrm{M}$ or greater. The hyperresponsiveness of the papillary muscle contraction of the reserpine-treated animals to histamine was abolished in the presence of 1 $\mu \mathrm{M}$ cimetidine, but not attenuated in the presence of $1 \mu \mathrm{M}$ diphenhydramine. This hyperresponsiveness was not modified by $1 \mu \mathrm{M}$ bunazosin or $1 \mu \mathrm{M}$ propranolol. The results suggest that $\mathrm{H}_{2}$-receptor mediated action plays a role in the hyperresponsiveness of cardiac muscles to histamine. (Jpn Heart J 35: 661-671, 1994)
\end{abstract}

Key words: Histamine Histamine-receptor Hyperresponsiveness Reserpine

T $\mathrm{T}$ is well recognized that cardiac muscles respond to catecholamines and reveal positive inotropic action. Pretreatment of animals including guinea pigs and rabbits') with reserpine has been shown to alter sensitivity of cardiac muscles to catecholamines. That is, pretreatment with reserpine induces a hyperresponsiveness of the positive inotropic and chronotropic actions in response to catecholamines. ${ }^{1-3)}$ This hypersensitivity is recognized to be due to depletion of cardiac norepinephrine stores and/or postjunctional hypersensitivity. ${ }^{4-6)}$ Cardiac muscles, in addition to responding to catecholamines, respond to

From the Department of Pharmacology, Tokyo College of Pharmacy, Hachioji, Japan.

Address for correspondence: Satoshi Takeo, Ph.D., Department of Pharmacology, Tokyo College of Phar macy, 1432-1, Horinouchi, Hachioji, Tokyo 192-03, Japan.

Received for publication May 25, 1994.

Accepted July 13, 1994. 
histamine, which is mediated by cardiac histaminergic receptors. ${ }^{7)}$ Reserpine treatment has also been shown to sensitize the guinea pig heart muscle contractile response to histamine. ${ }^{89}$ (9) The exact mechanism underlying such sensitization of cardiac muscles to histamine has not been fully understood. The present study was undertaken to characterize reserpine-induced hyperresponsiveness of cardiac muscles to histamine.

\section{Materials and Methods}

Treatment with reserpine: Hartley guinea pigs of either sex, weighing 250 to $350 \mathrm{~g}$, were used in the present study. The animals were fed ad libitum with tap water and commercial chow and maintained at $22 \pm 2{ }^{\circ} \mathrm{C}$ with a constant humidity of $55 \pm 5 \%$ before and during the experiment, according to the Guidelines for Experimental Animal Care issued by the Prime Minister's Office of Japan. The animals were treated with an intraperitoneal injection of $5 \mathrm{mg} / \mathrm{kg}$ of reserpine. ${ }^{10}$ Twenty-four hours after treatment, the guinea pigs were lightly anesthetized with ether and stunned by a blow to the head and their hearts were isolated for the subsequent studies. Guinea pigs that were not treated with reserpine served as controls.

Measurement of myocardial norepinephrine content: Guinea pigs were anesthetized with intraperitoneal administration of $35 \mathrm{mg} / \mathrm{kg}$ pentobarbital. The animals were ventilated with air by an artificial respirator (SN-480-7, Shinano Seisakusho, Tokyo, Japan) at a constant rate of 72 strokes/min with a stroke volume of $3.0 \mathrm{~m} l$. Immediately after thoracotomy, the hearts were clamped with Wollenberger tongs pre-cooled with liquid nitrogen and then immersed in liquid nitrogen. The frozen tissue was wcighed and pulverized in a stainless-steel centrifuge tube with a stainless-steel plunger under liquid nitrogen cooling. The pulverized sample was homogenized with a Polytron homogenizer in a solution of $0.2 \mathrm{~N} \mathrm{HClO}_{4}+0.1 \mu \mathrm{M}$ ethylenediaminetetraacetate (EDTA). After centrifugation of the extract at $10,000 \times \mathrm{g}$ for $15 \mathrm{~min}$, the final supernatant fluid was subjected to HPLC analysis. The supernatant fluid was separated through an ODS-column (Eicompak MA-5 ODS, Eicom, Kyoto, Japan), of 4.6 $\mathrm{mm}$ diameter and $150 \mathrm{~mm}$ length, by an elution with $100 \mathrm{mM}$ citrate- $100 \mathrm{mM}$ sodium acetate containing $15 \%$ methanol, $230 \mathrm{mg} / l$ sodium octanesulfonate and

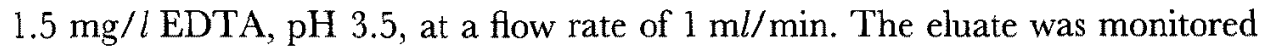
by an electrochemical detector (ECD-100, Eicom Inc., Kyoto Japan).

Perfusion of hearts: Perfusion of isolated guinea pig hearts was undertaken according to a modified method of Takeo et al. ${ }^{11)}$ Briefly, after thoracotomy, guinea pig hearts were isolated and perfused at $37^{\circ} \mathrm{C}$ with a constant flow rate of $36 \mathrm{ml} / \mathrm{min} / \mathrm{kg}$ of body weight with Krebs-Henseleit solution of the following 
composition (mM): $\mathrm{NaCl} 120, \mathrm{KCl} 4.8, \mathrm{KH}_{2} \mathrm{PO}_{4}$ 1.2, $\mathrm{MgSO}_{4}$ 1.2, $\mathrm{CaCl}_{2}$ 1.25, $\mathrm{NaHCO}_{3} 25$, glucose 11. The Krebs-Henseleit solution was equilibrated with a gas mixture of $95 \% \mathrm{O}_{2}+5 \% \mathrm{CO}_{2}$ before and throughout the experiment. The heart was preloaded with an initial resting tension of $1.50 \mathrm{~g}$. Cardiac contractile force was estimated by monitoring isometric tension development by means of a force displacement transducer (TB-611T, Nihonkohden, Tokyo, Japan) which was connected to a hook attached to the apex of the heart. Heart rate measurement was triggered from the isometric tension development by a cardiotachometer (AT-601G, Nihonkohden, Tokyo, Japan). Changes in cardiac contractile force and heart rate were recorded on a thermal pen recorder (MT645G, Nihonkohden, Tokyo, Japan). Histamine was injected to the heart in less than $0.1 \mathrm{~m} l$ saline through an aortic cannula.

Contractile activity of isolated papillary muscle: After the heart was isolated, the papillary muscle of the left ventricle was rapidly dissected and suspended in a glass organ bath filled with a Krebs-Henseleit solution as described above. The medium was equilibrated with a gas mixture of $95 \% \mathrm{O}_{2}+5 \% \mathrm{CO}_{2}$. The preparation was suspended with a small hook and connected to an isometric force-displacement transducer (TB-611T, Nihonkohden, Tokyo, Japan). An initial resting tension of $0.50 \mathrm{~g}$ was applied. The preparation was allowed to equilibratc for $60 \mathrm{~min}$ at $30^{\circ} \mathrm{C}$. The isolated papillary muscle was electrically stimulated at a rate of $1 \mathrm{~Hz}$ (approximately 1.2-fold threshold stimulus) with a duration of $1 \mathrm{msec}$. Histamine and various receptor blockers were applied to the organ bath in which the papillary muscle preparations were suspended.

To examine the sensitivity of the papillary muscle to extracellular calcium, papillary muscles from control and reserpine-treated guinea pigs were exposed to $1 \mu \mathrm{M}$ histamine in the medium containing various concentrations of calcium chloride $(0.3$ to $1.25 \mathrm{mM})$, and the tension development was determined in the same manner as above.

Statistics: Results are expressed as the mean \pm S.E.M. Statistical significance was calculated using the Student's t-test when two groups were compared, or analysis of variance followed by Dunnett's t-test when three or more groups were compared. Results with a probability of $5 \%$ or less were considered to be statistically significant $(p<0.05)$.

\section{Results}

Effect of treatment with reserpine on myocardial norepinephrine content: In the first set of experiments, myocardial norepinephrine content of reserpinetreated and control guinea pigs was determined 24 hours after treatment. The norepinephrine content of control animals was $0.91 \pm 0.04 \mu \mathrm{g} / \mathrm{g}$ frozen tissue 


\section{Control}

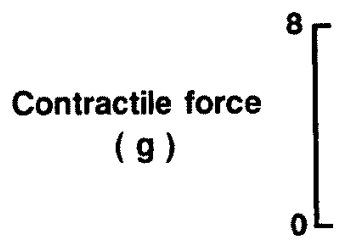

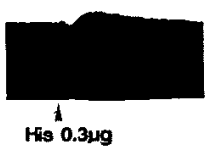

$\begin{array}{cc}\text { Contractile force } & \\ (\mathrm{g}) & { }_{0}^{8}[\end{array}$

$$
\text { ins } 0.34
$$

Reserpine treated
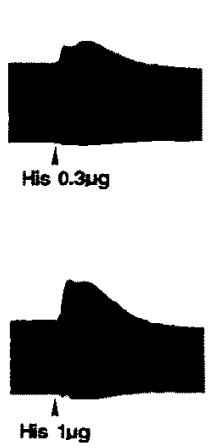

$5 \mathrm{~min}$

Figure 1. Typical responses in contractile force to 0.3 and $1 \mu \mathrm{g}$ histamine (His) in perfused hearts isolated from both control (left panel) and reserpine-treated (right panel) guinea pigs.

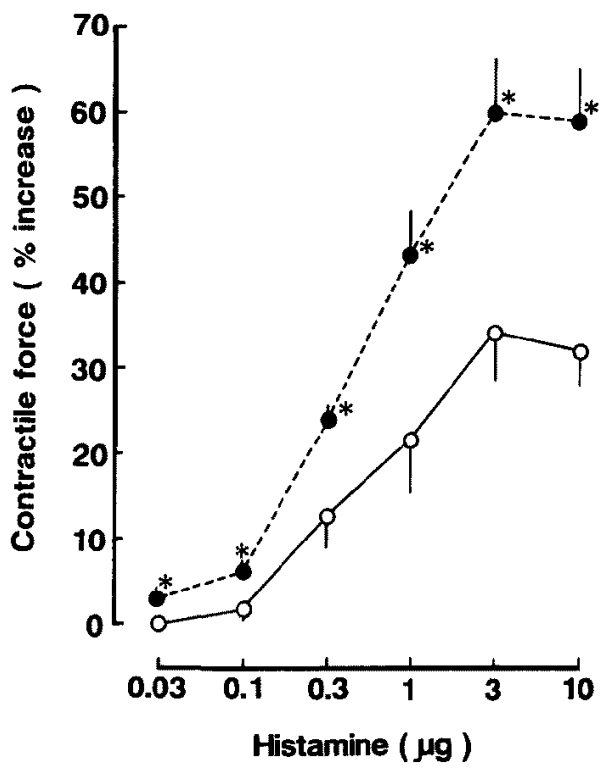

Figure 2. Effects of 0.03 to $10 \mu \mathrm{g}$ histamine on contractile force of perfused hearts isolated from both control $(O)$ and reserpine-pretreated $(\mathbf{O})$ guinea pigs. Values in the figure indicate percent increase in contractile force of the isolated perfused hearts. Each value represents the mean \pm S.E.M. of 4 experiments. The initial values of developed tension in the untreated and reserpine-treated hearts were $3.4 \pm 0.3$ and $3.3 \pm 0.1$ $g$, respectively. *Significantly different from the corresponding control group $(p<0.05)$. 
Table. Changes in Heart Rate and Perfusion Pressure of the Perfused Heart Isolated from Reserpine-treated and Control Guinea Pigs

\begin{tabular}{lcccccc}
\hline & \multicolumn{7}{c}{ Doses of histamine $(\mathrm{mg})$} \\
& 0.03 & 0.1 & 0.3 & 1 & 3 & 10 \\
\hline Heart rate & & & & & & \\
$\quad$ Control & $0 \pm 0$ & $0.6 \pm 0.6$ & $11.3 \pm 1.8^{*}$ & $23.9 \pm 3.9^{*}$ & $41.6 \pm 4.3^{*}$ & $44.5 \pm 4.9^{*}$ \\
$\quad \begin{array}{l}\text { Reserpine-treated } \\
\text { Perfusion pressure }\end{array}$ & $0 \pm 0$ & $1.0 \pm 0.5$ & $13.1 \pm 1.8^{*}$ & $26.4 \pm 4.3^{*}$ & $45.3 \pm 4.5^{*}$ & $51.2 \pm 4.8^{*}$ \\
$\quad$ Control & & & & & & \\
$\quad$ Reserpine-treated & $0 \pm 0$ & $2.1 \pm 1.2$ & $10.1 \pm 5.0$ & $13.5 \pm 5.6$ & $20.0 \pm 4.7^{*}$ & $22.8 \pm 5.4^{*}$ \\
& & $3.4 \pm 1.1$ & $19.8 \pm 5.7$ & $24.9 \pm 7.7$ & $24.3 \pm 5.8^{*}$ & $28.8 \pm 6.1^{*}$ \\
\hline
\end{tabular}

Values are expressed as \% increase. Initial values of heart rate of control and reserpine-treated animals were $161 \pm 9$ and $179 \pm 17$ beats $/ \mathrm{min}$, and those of perfusion pressure, $50.9 \pm 2.6$ and $54.4 \pm 4.9 \mathrm{~mm} \mathrm{Hg}$, respectively $(n=4)$. Each value represents the mean \pm S.E.M. of 4 experiments. *Significantly different from baseline value $(p<0.05)$. There were no significant differences in these variables between reserpine-treated and control animals.

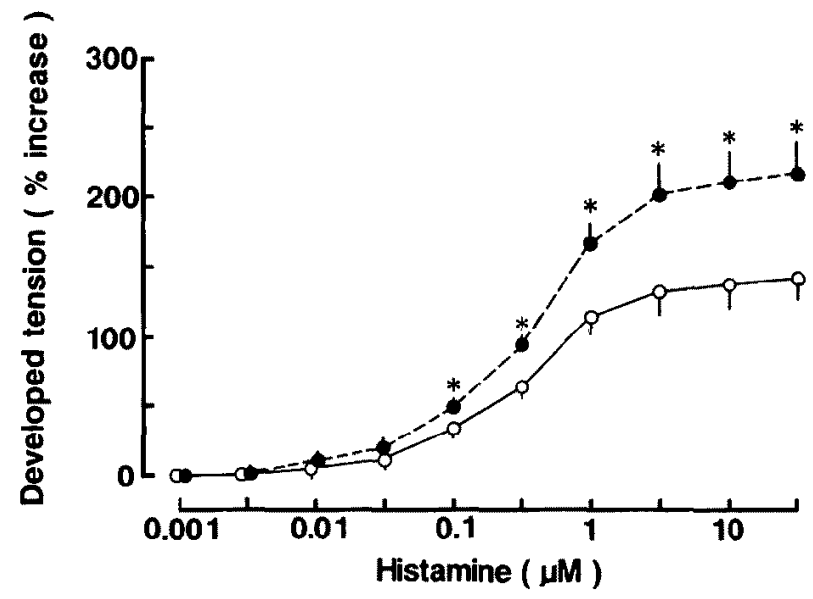

Figure 3. Effects of histamine on developed tension of left ventricular papillary muscles isolated from either control (O) or reserpine-pretreated (O) guinea pigs at concentrations ranging from 0.001 to $30 \mu \mathrm{M}$. Values in the figure indicate percent increase in developed tension at various concentrations of histamine. Each value represents the mean \pm S.E.M. of 6 to 9 experiments. The initial values of developed tension in the untreated and reserpine-treated papillary muscles were $288 \pm 32$ and $262 \pm 32 \mathrm{mg}$, respectively. ${ }^{*}$ Significantly different from the untreated group $(p<0.05)$.

$(n=5)$, whereas no detectable myocardial norepinephrine (less than $0.01 \mu \mathrm{g} / \mathrm{g}$ frozen tissue) was observed in the reserpine-treated animals $(n=6)$.

Responses of contractile force, heart rate and perfusion pressure of isolated perfused hearts to histamine: Typical tracings of contractile force of the isolated perfused heart in the presence and absence of 0.3 and $1 \mu \mathrm{g}$ histamine are shown in Figure 1. Cardiac contractile force declined transiently when the control heart was exposed to $0.3 \mu \mathrm{g}$ histamine and augmented thereafter. The control heart did not show any negative inotropic effect when $1 \mu \mathrm{g}$ or greater 
histamine was administered to the heart. The effects of various doses of histamine $(0.03$ to $10 \mu \mathrm{g})$ on peak cardiac contractile force development of perfused, reserpine-treated and control guinea pigs are shown in Figure 2. The cardiac contractile force of control guinea pig hearts was increased in a dose-dependent manner when histamine $(0.1$ to $3 \mu \mathrm{g})$ was injected into the heart. When 0.3 to 10 $\mu \mathrm{g}$ of histamine were applied to the reserpine-treated heart, the histamine-induced increase in contractile force was potentiated as compared with that of the control heart. Changes in heart rate and perfusion pressure of the perfused hearts from control and reserpine-treated animals are shown in the Table. Heart rate of the perfused hearts of both animals was increased with $0.3 \mu \mathrm{g}$ or greater of histamine. The perfusion pressure was also increased with the increased doses of histamine. There were no differences in the increases in heart rate and perfusion pressure between reserpine-treated and control animals.

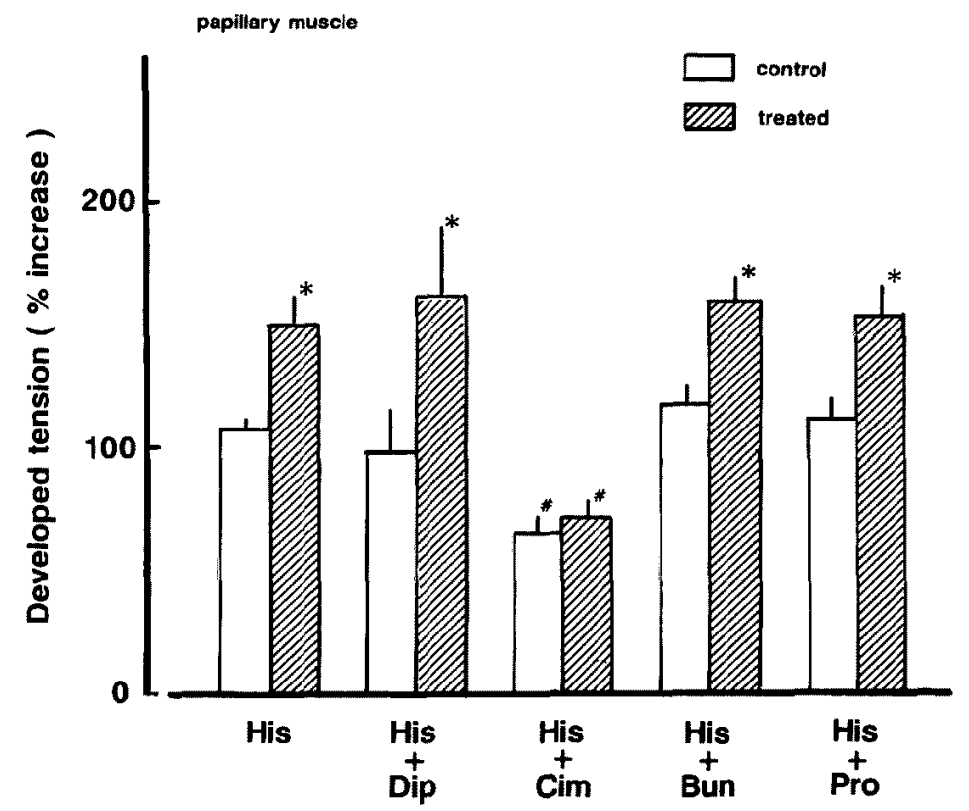

Figure 4. Effects of histaminergic blockers and adrenergic blockers on the histamine-induced increase in developed tension of left ventricular papillary muscles isolated from either control (open column) or reserpine-pretreated (striped column) guinea pigs. The blockers ( $1 \mu \mathrm{M}$ diphenhydramine (Dip), $1 \mu \mathrm{M}$ cimetidine (Cim), $1 \mu \mathrm{M}$ bunazosin (Bun), or $1 \mu \mathrm{M}$ propranolol (Pro) were administered before exposure to $1 \mu \mathrm{M}$ histamine (His). The values indicate percent changes of developed tension with $1 \mu \mathrm{M}$ histamine. The initial values of developed tension of control and reserpinetreated hearts were similar to those in Figure 3. Each value represents the mean \pm S.E.M, of 4 to 6 experiments. *Significantly different from the corresponding control group and "significantly different from the group receiving histamine alone $(p<0.05)$. 
Developed tension of isolated papillary muscle: Tension development of isolated papillary muscles was measured in the presence and absence of various concentrations of histamine ranging from 0.001 to $30 \mu \mathrm{M}$ (Figure 3 ). The developed tension of papillary muscles from the control animals was increased by 0.1 $\mu \mathrm{M}$ or greater of histamine. In the reserpine-treated guinea pig papillary muscle, the histamine-induced increase in developed tension was significantly potentiated as compared with that of the control papillary muscle (Figure 3). The $\mathrm{EC}_{50}(-\log$ $[\mathrm{M}]=6.4$ ) of the reserpine-treated animals was almost the same as that of the control animals.

To determine if a receptor-mediated action of the papillary muscles contributes to the potentiation of developed tension, adrenergic and histaminergic receptor blockers were applied to the muscle (Figure 4). The positive inotropic response of the papillary muscle of reserpine-treated animals was potentiated $(151 \pm 12 \%$ ) upon exposure to $1 \mu \mathrm{M}$ histamine as compared with that of control animals $(107 \pm 6 \%)$. Treatment with $1 \mu \mathrm{M}$ diphenhydramine did not modify the potentiation of the histamine-induced increase in developed tension of the papillary muscle. Treatment with $1 \mu \mathrm{M}$ cimetidine completely abolished the potentiation of histamine-induced positive inotropy of the reserpinized animals. The potentiated positive inotropic action of the papillary muscle in the reserpinized

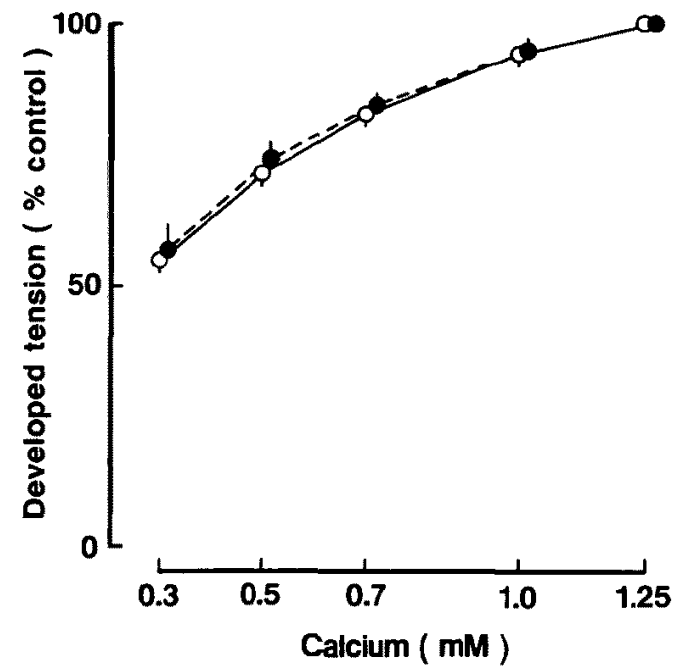

Figure 5. Changes in developed tension of left ventricular papillary muscles isolated from either control $(O)$ or reserpine-pretreated $(0)$ guinea pigs in the buffer containing different concentrations of extracellular calcium (0.3 to $1.25 \mathrm{mM}$ ). Values are expressed as percent control produced by $1 \mu \mathrm{M}$ histamine in the presence of $1.25 \mathrm{mM}$ $\mathrm{CaCl}_{2}$. The initial values of control and reserpine-treated hearts were similar to those in Figure 3. Each value represents the mean \pm S.E.M. of 4 experiments. 
animals upon exposure to $1 \mu \mathrm{M}$ histamine was not altered by either $1 \mu \mathrm{M}$ bunazosin (an alpha $a_{1}$-adrenoceptor blocker) or $1 \mu \mathrm{M}$ propranolol (a betaadrenoceptor blocker).

In order to examine the responsiveness of histamine-induced cardiac muscle contraction to calcium, the papillary muscles of control and reserpine-treated animals were exposed to $1 \mu \mathrm{M}$ histamine in the presence of different concentrations of extracellular calcium (Figure 5). The histamine-induced increases in developed tension of control and reserpine-treated guinea pig papillary muscles at different concentrations of extracellular calcium chloride $(0.3$ to $1.0 \mathrm{mM})$ were compared with those produced in the presence of $1.25 \mathrm{mM}$ calcium chloride. There were no changes in the responsiveness of the histamine-induced increase in developed tension of the papillary muscle to extracellular calcium regardless of treatment with or without reserpine.

\section{Discussion}

In the present study we have shown that treatment of guinea pigs with reserpine resulted in a depletion of myocardial norepinephrine and an induction of hyperresponsiveness of cardiac contractility to histamine. Our findings regarding these pathophysiological changes of reserpine-treated guinea pig hearts are comparable to the previous observations on reserpine-induced depletion of catecholamines and hypersensitivity of cardiac muscles to catecholamines as described in the Introduction. Reserpine-induced hyperresponsiveness of guinea pig cardiac muscles to histamine was also observed in papillary muscle preparations. Since left ventricular muscles contribute to the whole heart contractility to a greater degree than do atrial muscles, the reserpine-induced hyperresponsiveness may be primarily attributed to the left ventricular muscle.

It is well recognized that there are two histaminergic receptors in hearts, $\mathrm{H}_{1}$ - and $\mathrm{H}_{2}$-receptors, both of which are considered to be involved mainly in the positive inotropic effects of cardiac muscles. ${ }^{7,12,13)} \mathrm{H}_{2}$-receptor-mediated positive inotropic effects are associated with an increase in cyclic AMP levels, ${ }^{714)}$ whereas $\mathrm{H}_{1}$-receptor-mediated positive inotropic effects are independent of cyclic AMP levels. ${ }^{15)}$ In contrast to this, Zavecs and Levi ${ }^{16)}$ have shown that isolated guinea pig hearts exhibit negative inotropic action in the presence of the $\mathrm{H}_{2}$-receptor blocker, cimetidine. This suggests that guinea pig hearts have a potential to exert both negative and positive inotropic actions through the $\mathrm{H}_{1}$-receptor. This notion is supported by our findings of the transient decline in contractile force of the perfused heart following administration of $0.3 \mu \mathrm{g}$ histamine. The transient negative inotropy may be a manifestation of the $\mathrm{H}_{1}$-receptor mediated action of histamine, which only appears under low levels of exogenous histamine. When 
hearts are exposed to high levels of exogenous histamine, the $\mathrm{H}_{2-}$ and/or $\mathrm{H}_{1}$ receptor-mediated positive inotropic action may overcome the $\mathrm{H}_{1}$-receptor-mediated negative inotropic action.

We found that the hyperresponsiveness of papillary muscles of the reserpinized animal was not modified by diphenhydramine, an $\mathrm{H}_{1}$-blocker, but was abolished by cimetidine, an $\mathrm{H}_{2}$-blocker. The results suggest that $\mathrm{H}_{2}$-receptor mediated action plays a role in the potentiation of histamine-induced positive inotropy of cardiac muscles of the reserpine-treated animal. Furthermore, we found that the histamine-induced positive inotropic effects of the papillary muscle of control as well as reserpine-treated animals were not modified by either bunazosin, an alpha 1 -adrenoceptor blocker, or propranolol, a beta-adrenoceptor blocker. This suggests that the hyperresponsiveness to histamine observed in the present study is unrelated to adrenergic receptors.

It is recognized that the reserpine-induced hypersensitivity of guinea pig hearts to catecholamines is due to alterations in the sensitivity of cardiac muscle contraction to extracellular calcium., ${ }^{9,17,18)}$ Thus, a possible involvement of alterations in the sensitivity of cardiac muscles to calcium is considered in the hyperresponsiveness observed in the present study. We found, however, that the hyperresponsiveness of papillary muscle contraction of the reserpine-treated guinea pig to histamine was not dependent on extracellular calcium concentrations.

Several reports have shown that the hypersensitivity of guinea pig cardiac muscle contraction to histamine was associated with increases in phosphorylase activity and cyclic AMP formation. ${ }^{8,9}$ Thus, these events may be involved in the reserpine-induced hyperresponsiveness of cardiac muscle contraction to histamine. Furthermore, there is evidence that the number of beta-adrenoceptors in rat, ${ }^{19,20)}$ rabbit, $^{21)}$ and guinea pig hearts ${ }^{20,22)}$ is increased upon treatment with reserpine or 6-hydroxydopamine. Changes in the number of histamine receptors are also conceivable under the present experimental conditions. Such molecular and cellular alteration may be one of the possible mechanisms underlying the hyperresponsiveness of cardiac muscles of the reserpinized animals in the present study.

In conclusion, the present study has shown that treatment of guinea pigs with reserpine induced a depletion of myocardial catecholamines and a potentiation of cardiac response to histamine. The hyperresponsiveness is conceived to be mediated via $\mathrm{H}_{2}$-receptors. Obviously, it would be premature to consider the significance of the hyperresponsiveness of cardiac muscles to histamine merely on the basis of the experimental results. It is speculative that hyperresponsiveness to histamine plays a role in enhancement of cardiac contractility in animals and patients whose cardiac responsiveness to catecholamines is blunted. In this sense, 
it is recognized that animals and patients with chronic heart failure following myocardial infarction and hypertension reveal decreased cardiac responsiveness to catecholamines due to the occurrence of desensitization and down-regulation of myocardial beta-adrenoceptors. ${ }^{23}$

\section{REFERENCES}

1. Trendelenburg U: Mechanisms of supersensitivity and subsensitivity to sympathomimetic amines. Pharmacol Rev 18: 629, 1966

2. Hugings PM, Fleming WW: A relatively nonspecific supersensitivity in aortic strips resulting from pretreatment with reserpine. J Pharmacol Exp Ther 156: 207, 1966

3. Westfall DP, Fleming WW: Sensitivity changes in the dog heart to norepinephrine, calcium and aminophylline resulting from pretreatment with reserpine. J Pharmacol Exp Ther 159: 98, 1968

4. Burn JH, Rand MJ: Noradrenaline in artery walls and its dispersal by reserpine. Br Med J 1: 903 , 1958

5. Fleming WW: A comparative study of supersensitivity to norepinephrine and acetylcholine produced by denervation, decentralization and reserpine. Ergeb Physiol Biol Chem Exp Pharmacol 68: 55, 1963

6. Taylor DA, Westfall DP, Fleming WW: The effect of reserpine treatment on the chronotropic and inotropic sensitivities of the perfused guinea-pig hearts to norepinephrine and calcium. Eur J Pharmacol 29: 102, 1974

7. Reihardt D, Schmidt U, Brodde OF, Schumann $\mathrm{HJ}: \mathrm{H}_{1}$ - and $\mathrm{H}_{2}$-receptor mediated responses to histamine on contractility and cyclic AMP of atrial and papillary muscles from guinea pig hearts. Agent Actions 7: 1, 1977

8. McNeil JH, Schulze S: Reserpine-induced supersensitivity to histamine activated cardiac phosphorylase and cardiac contractility. Res Comm Chem Pathol Pharmacol 3: 3391972

9. Rodgers RL, McNeill JH: Effect of reserpine pretreatment on guinea pig ventricular performance and responsiveness to inotropic agents. J Pharmacol Exp Ther 221: 721, 1982

10. Schwartz A, Lee SK: Effect of reserpine on heart mitochondria. Nature (London), 188: 948, 1960

11. Takeo S, Yamada H, Tanonaka K, Sunagawa N: Possible involvement of membrane-stabilizing action in beneficial effect of beta-adrenoceptor blocking agents on hypoxic and posthypoxic myocardium. J Pharmacol Exp Ther 254: 847, 1990

12. Steinberg MI, Holland DR: Separate receptors mediating the positive inotropic and chronotropic effect of histamine in guinea-pig atria. Eur $\mathrm{J}$ Pharmacol 34: 95, 1975

13. Verma $\mathrm{SC}, \mathrm{McNeill} \mathrm{JH}$ : Cardiac histamine receptors; differences between left and right atria and right ventricle. J Pharmacol Exp Ther 200: 352, 1977

14. McNeil JH, Verma SC: Histamine effects on cardiac contractility. Res Comm Chem Pathol Pharmacol 3: 339, 1972

15. Osnes JB, Oye I: Relationship between cyclic AMP metabolism and inotropic response of perfused rat hearts to phenylephrine and other adrenergic amines. Adv Cyclic Nucleotide Res 5: 395, 1980

16. Zavecs JH, Levi R: Histamine-induced negative inotropism: Mediation by $\mathbf{H}_{1}$-receptors. J Pharmacol Exp Ther 206: 274,1978

17. Tenner TE, Carrier, O Jr: Reserpine-induced supersensitivity to the chronic and inotropic effects of calcium in rabbit atria. J Pharmacol Exp Ther 205: 183, 1978

18. Tenner TE, McNeil JH, Carrier O Jr: The role of calcium in supersensitivity to the inotropic effects of norepinephrine. Eur J Pharmacol 50: 359, 1978

19. Nomura $Y$, Kajiyama $H$, Segawa $T$ : Hypersensitivity of cardiac beta-adrenergic receptors after neonatal treatment of rats with 6-hydroxydopa. Eur J Pharmacol 66: 225, 1980

20. Chess-Williams RG, Broadley KJ, Sheridan DJ: Calculated and actual changes in beta-adrenoceptor number associated with increases in rat and guinea pig cardiac muscle. J Pharm Pharmaocol 38: 902, 1986

21. Tenner TE, Jr, Mukherjee A, Hester RK: Reserpine-induced supersensitivity and the proliferation of 
cardiac $\beta$-adrenoceptors. Eur J Pharmacol 77: 61, 1982

22. Chess-Williams RG, Grassby PF, Culling W, Penny W, Broadley KJ, Sheridan DJ: Cardiac postjunctional supersensitivity to beta-agonists after chronic chemical sympathectomy with 6hydroxydopamine. Naunyn-Schmiedeberg's Arch Pharmacol 329: 162, 1985

23. Muntz KH, Zhao M, Miller JC: Downregulation of myocardial $\beta$-adrenergic receptors; receptor subtype selectivity. Circ Res 74: 369, 1994 